\title{
Post-seismic Effectiveness of the Strengthening Work Carried Out with GFRP Applied to Historical Masonry Buildings: The Case Study of the Spoleto Cathedral
}

\author{
Alessandro Grazzini ${ }^{1 *}$, Stefano Agnetti ${ }^{2}$ \\ ${ }^{1}$ Assistant Professor, Department of Structural Geotechnical and Building Engineering, Politecnico di Torino. ${ }^{\left({ }^{*}\right)}$ corresponding author: ales- \\ sandro.grazzini@polito.it \\ ${ }^{2}$ Civil Engineer Ph.D., Head of Technical Department, Kimia S.p.A., stefano.agnetti@kimia.it
}

\begin{abstract}
The sequence of major earthquakes that has affected Italy in recent decades has required the use of new materials and innovative techniques for the security of damaged buildings. Fiber Reinforced Polymer (FRP) represents a novelty in the field of seismic improvement techniques applicable also to historical masonry structures. The use of composite materials can respect the conservation principles of the monumental buildings. This study describes the effectiveness of the seismic improvement techniques carried out by means of FRP in the Spoleto Cathedral (Italy) after the 1997 Umbria-Marche earthquake. The strengthening work concerned the making safe of damaged vault structures by means of gluing fiberglass bands (GFRP). After 20 years, during the 2016 Amatrice-Norcia earthquake, near Spoleto, the cathedral reinforced with the GFRP bands has not suffered any damage demonstrating the effectiveness of the seismic strengthening techniques.
\end{abstract}

Keywords: Historical buildings; Seismic improvement; GFRP; Strengthening work, Fiberglass band.

\section{Introduction}

The seismic vulnerability of the existing building heritage represents a complex problem within a highly seismic area. Recently the Centre area of Italy was hit by a big seismic sequence that in 2016 destroyed the village of Amatrice (6.0 magnitude) and caused much damage to Norcia (6.5 magnitude). Many historical buildings collapsed or were seriously damaged ${ }^{[1]}$. The Central Italy had been hit by other seismic events of similar intensity and destruction already 40 years ago (1979 Valnerina earthquake, 5.8 magnitude) and 20 years ago (1997 Umbria-Marche earthquake, 6.0 magnitude). Therefore it is very interesting to verify how the strengthening techniques, applied after the previous earthquakes, have responded to the stresses of the last earthquake (2016
Amatrice-Norcia). It is also an opportunity to analyse how these strengthening techniques have evolved over time, with the introduction of lighter and more resistant modern materials, adaptable to any context, even the monumental artistic one. Many types of damage and vulnerability can also be recovered with innovative and lighter materials, such as FRP bands. The choice of strengthening materials must be very careful so that materials with physical-mechanical characteristics compatible with the historical masonry support are applied ${ }^{[2]}$.

After the 1997 Umbria-Marche earthquake, a detailed experimentation of the FRP application also began on historical masonry structures, considering the need to strength a large number of damaged buildings ${ }^{[3]}$. 
Different types of composite materials have been commercialized and can easily be applied to masonry mainly by gluing ${ }^{[4]}$.

A case study of the Spoleto Cathedral (Figure 1), damaged after the 1997 Umbria-Marche earthquake, was described. This monumental church was built at Spoleto (region of the Umbria, Italy) in the twelfth century and later its interior changed its architectural style in the seventeenth century ${ }^{[5]}$. The Spoleto Cathedral is one of the most important historical buildings in Umbria and in Italy. The church has received strengthening and seismic improvement work using also FRP materials.

\section{Seismic structural damages}

The damage caused by the last earthquakes in Cen- tral Italy highlighted the vulnerabilities present on the historical buildings, and the ineffectiveness of some strengthening techniques that proved useless to protect the buildings during the subsequent earthquakes ${ }^{[1]}$. Masonry cracks opened in previous earthquakes and simply sewn by cement injections, reopened and re-exposed the same vulnerabilities during the last 2016 Amatrice-Norcia earthquake (Figure 2). In some cases even the buildings strengthened by reinforced cement plasters not connected transversely collapsed to the next powerful earthquake. Seismic damage often regards out of plane mechanisms of the multi-leaf and not effectively connected masonry walls (Figure 3).

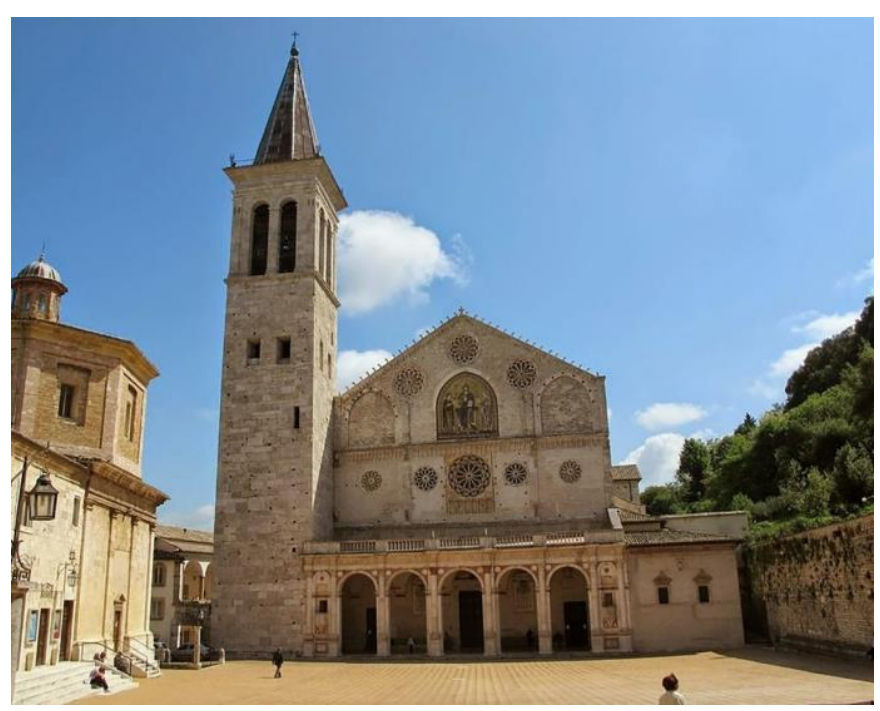

Figure 1. The Spoleto Cathedral.

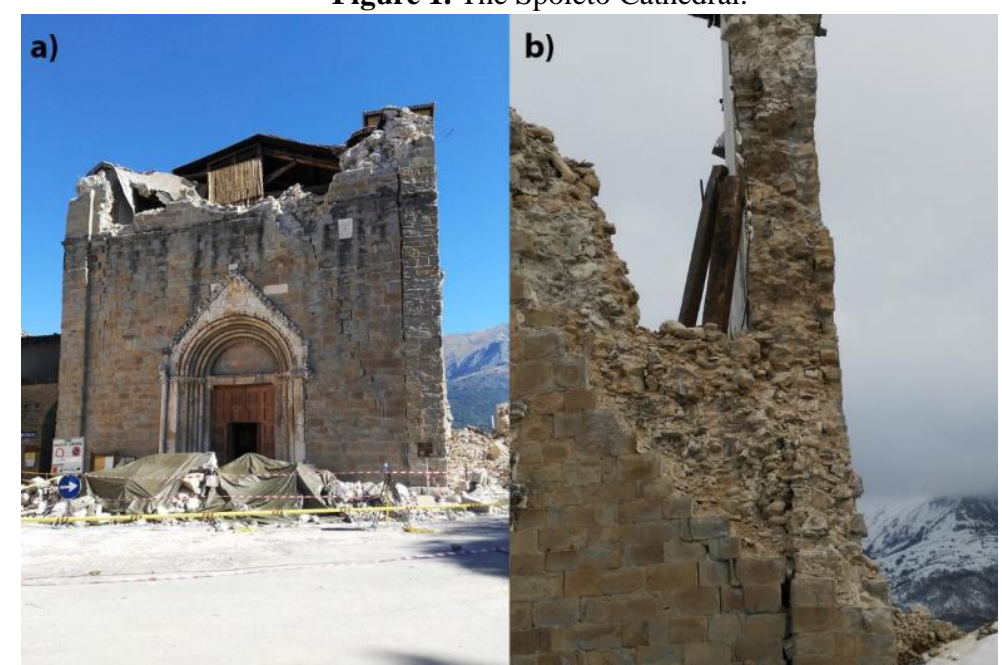

Figure 2. Collapse of the St. Agostino church in Amatrice (2016 earthquake): a) out of plane of the façade after the first seismic shock, which highlights the opening of a sub-vertical crack previously strengthened by cement injections after the 1979 Valnerina earthquake; b) opening and collapse of the failure in which it is possible to see the signs of previous cement injections. 


\section{New strengthening materials}

Fiber Reinforced Polymers (FRP) are structural systems constituted by an epoxy matrix (used both to glue and to impregnate the fibers) and by unit, bi or multi-directional fabrics made out of carbon fiber, glass fiber, basalt fiber. Thanks to their versatility and lightness, FRP can be used for: flexural and shear strengthening of reinforced concrete or wooden beams; confinement of reinforced concrete pillars and masonry columns in order to increase resistance and ductility (Figure 4); strengthening of weak connections beams/columns; flexural strengthening of floors; vaults, domes and arches strengthening both from the intrados or from the extrados (Figure 5); walls connections and strengthening.

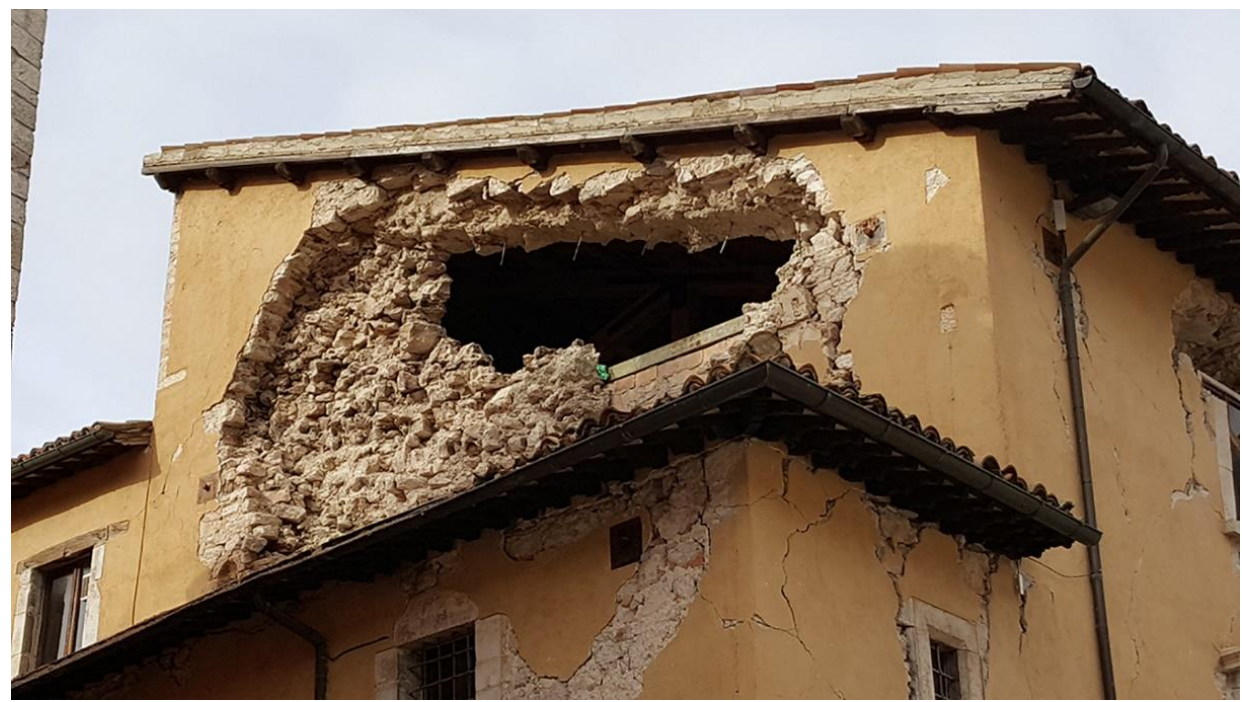

Figure 3. Out of plane collapse of a multi-leaf masonry wall (2016 Amatrice-Norcia earthquake).
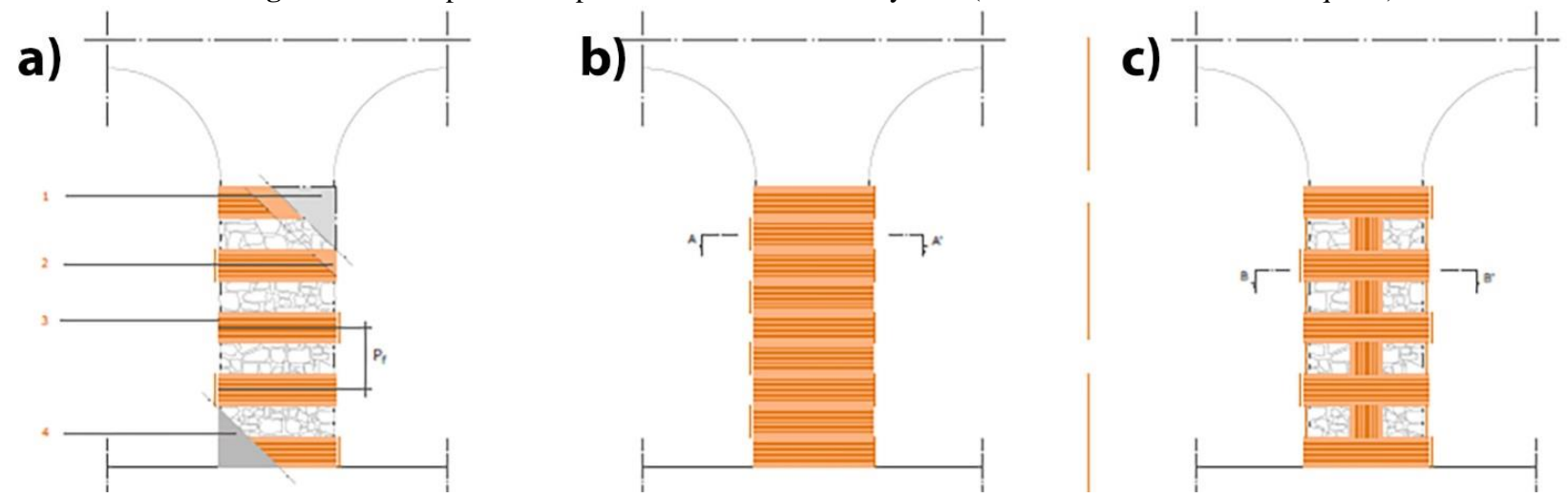

Figure 4. Different solutions for confinement of masonry columns by FRP wrap: a) discontinuous bandage; $b$ ) ous bandage; c) discontinuous wrapping with the addition of longitudinal strips.

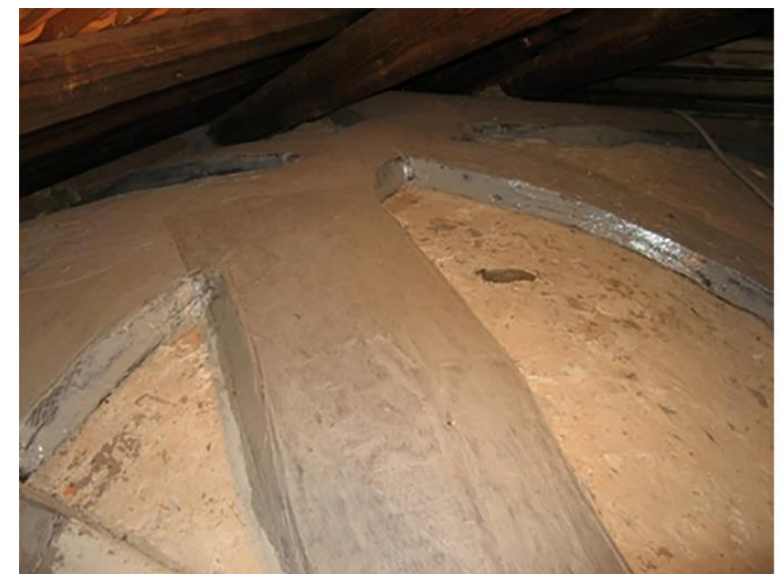

Composite Materials Research

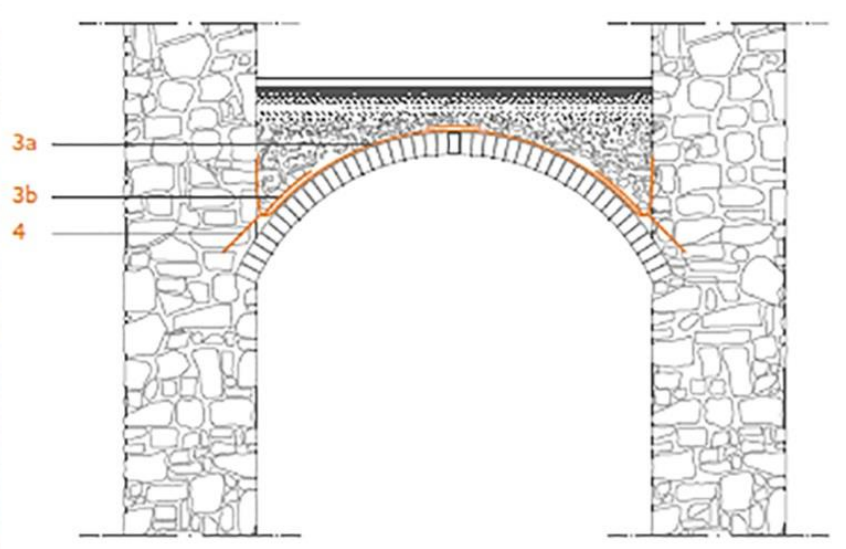


Figure 5. FRP Strengthening vault from the extrados.

Fiber Reinforced Polymer (FRP) is known as an excellent material for retrofitting, repairing and strengthening structural members. It is characterized by the following features: light weight material, corrosion resistant; available in various forms for field application, such as bar, sheet, strips and plate, and also available in long length thus eliminating the need for joints and splices; and can be cured within 24 hours when applied in the field. As can be seen in the schemes of the figures, often the collaboration of the fabric with the masonry surface is guaranteed not only by gluing but also by the application of special ropes which slit gluing to the resin of application of the composite fabric. The FRP bands can be used as a reinforcement circle building for the contrast of out of plane mechanisms of masonry vulnerable to seismic action (Figure 6), or for reinforcing masonry, increasing its shear and bending strength (Figure 7). The fabric in composite material has the enormous advantage of being able to adapt to the different curves of the walls.

\section{The case study of the Spoleto Cathedral}

After the 1997 Umbria-Marche earthquake, the Spoleto Cathedral was subjected to a detailed survey carried out in order to know the actual conditions of the monument about the structural and security aspects. The non-homogeneous distribution of the damages present in the various parts of the cathedral showed a different behaviour towards the seismic actions. So the seismic events have highlighted the structural weaknesses, also amplified by the absence of maintenance. The façade showed widespread degradation, mainly due to water infiltration. The main aisle instead suffered cracks on the barrel vault following the seismic action. In the left aisle there were diagonal cracks with respect to the axis of the church in correspondence with the cross-vault centreline. In the area of the high altar there were instead cracks in correspondence of the triumphal arch near the apse (Figure 8). In this arc there were produced deep cracks and tilted both in key and in the kidneys which produced a detachment of the central part of the arch up to the dome's turn. In the left transept there was a detachment between the barrel vault and the stiffening arches. The most serious damage occurred in the Chapel of the Blessed Sacrament which suffered cracks on the vertical walls and in particular at the openings.

The analysis of the cracking state and of the structural behavior of the Cathedral have inspired the choice of the restoration and seismic improvement work of the structures. The strengthening work was carried out between 1997 to 2002 on the central nave, the dome, the façade and the side aisles. Between 2002 and 2009, specific work was carried out involving the sacristy and the convent, thanks to private funding. In 2009, the aim of a second phase of strengthening work was to consolidate the side chapels, the transept coverings and to restore the plasterwork of the chapels and the façades of the bell tower. Composite materials were used to strength the vaults of the chapels and of the main nave. The interventions therefore had the purpose of recovering the static integrity and improving the structural behavior towards seismic actions. This work has allowed the restoration of the structural continuity in the damaged walls, the improvement of the mechanical characteristics and the seismic behavior of the individual structural elements and of the entire Cathedral. In the upper area of the central aisle, the interventions carried out mainly aimed at effectively consolidating the attic masonry between the vault and the roof slab by means of injections and reinforced perforations.

All strengthening materials were supplied by Kimia S.p.A. ${ }^{[6]}$. The barrel-vaulted cracks were stitched by means of fiberglass composite material (GFRP) to repair the existing cracks (Figure 9). In addition tie rods was put at the level of the top curb to prevent the out of plane phenomena (Figure 10). On the dome and on the lantern, strengthening works were carried out by means of injections (Figure 11) and reinforcement circle building.

As regards the façade, in order to improve its stability against out of plane mechanisms, a system of tie rods has been designed and implemented in order to improve the degree of constraint in the façade. For the sizing of the tie rods, various analyses were carried out, varying the rigidity of the tie rods themselves.

Glass fibres were used as intrados reinforcement of the triumphal arches present in the apse area, and for the extrados reinforcement of the vaults present in the central nave and in the side aisles ${ }^{[7]}$. Among the safety measures that affected the bell tower, fiberglass bandages were used. There are many advantages in fi- 
ber-reinforced composite materials: their applications are easy to create and extremely versatile, both for the recovery of the existing and the design of new structures.
The weight of the structure is not compromised by the application of FRP reinforcement.
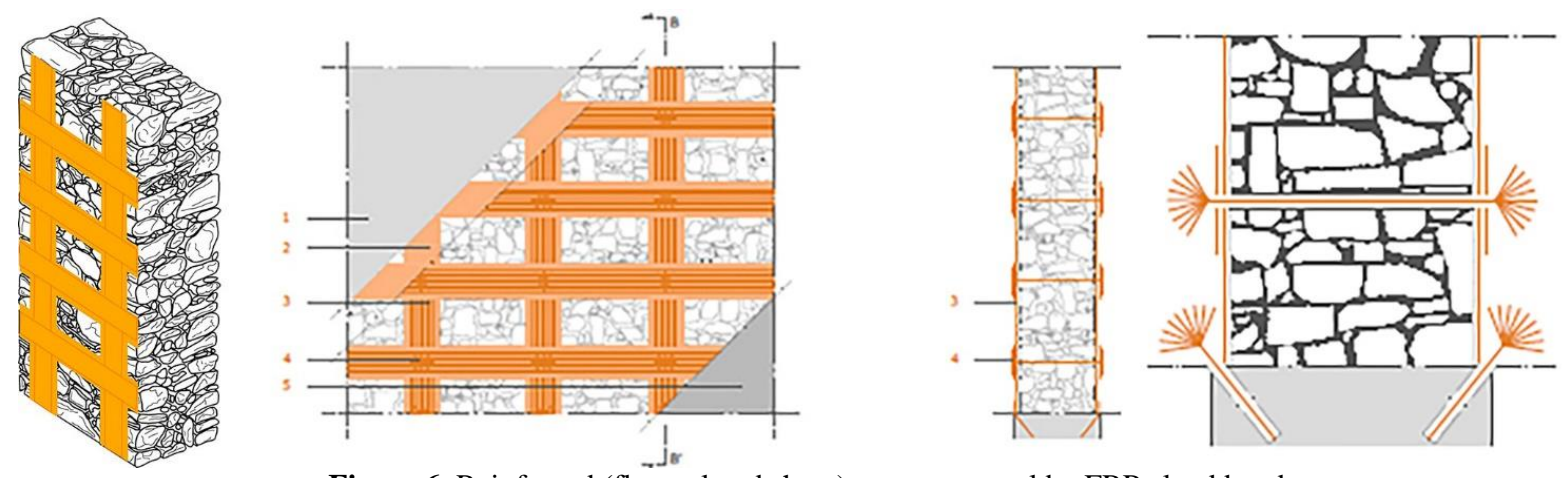

Figure 6. Reinforced (flexural and shear) masonry panel by FRP glued bands.

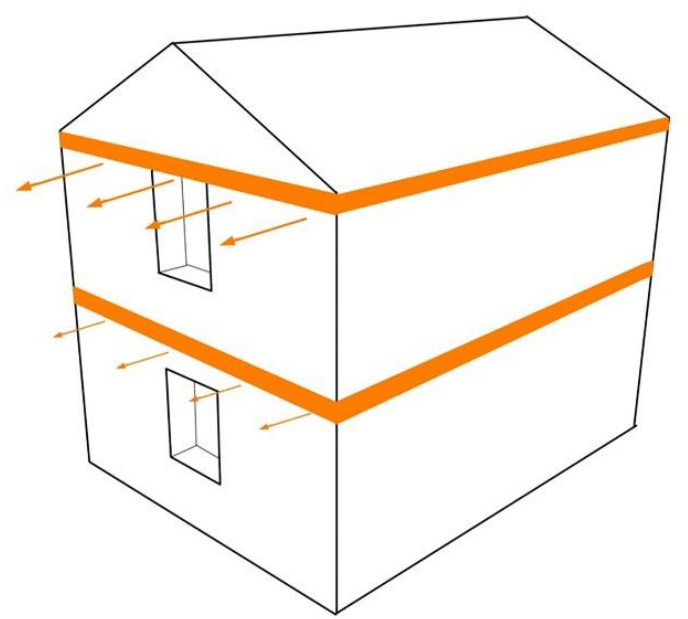

Figure 7. Reinforcement circle buildings made by FRP bands for the contrast of out of plane in masonry vulnerable to seismic action.

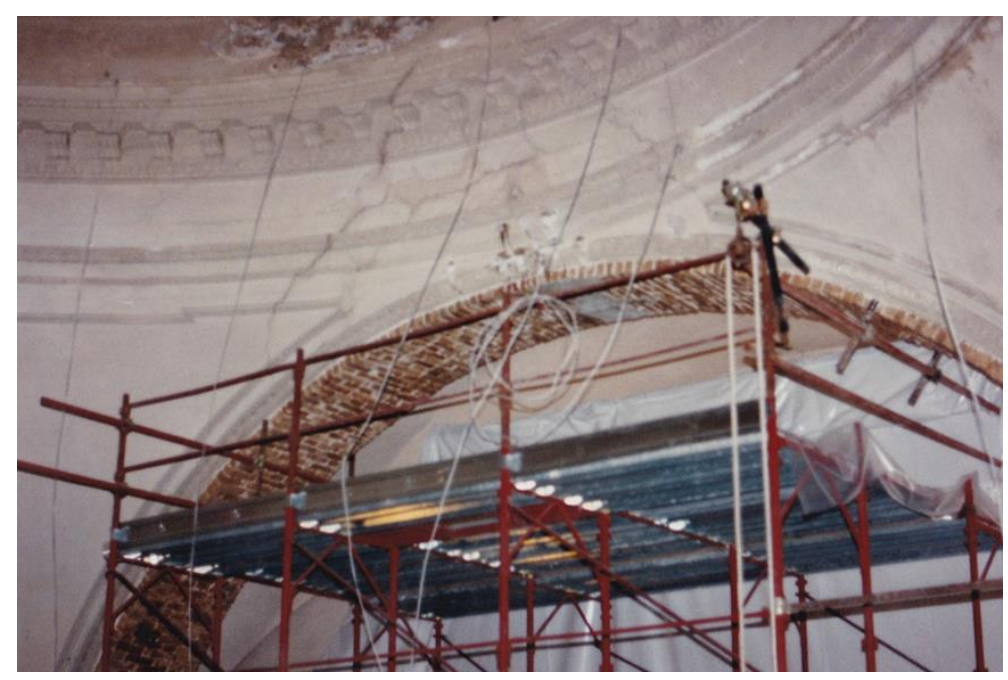

Figure 8. The cracks of the triumphal arch of the main nave. 


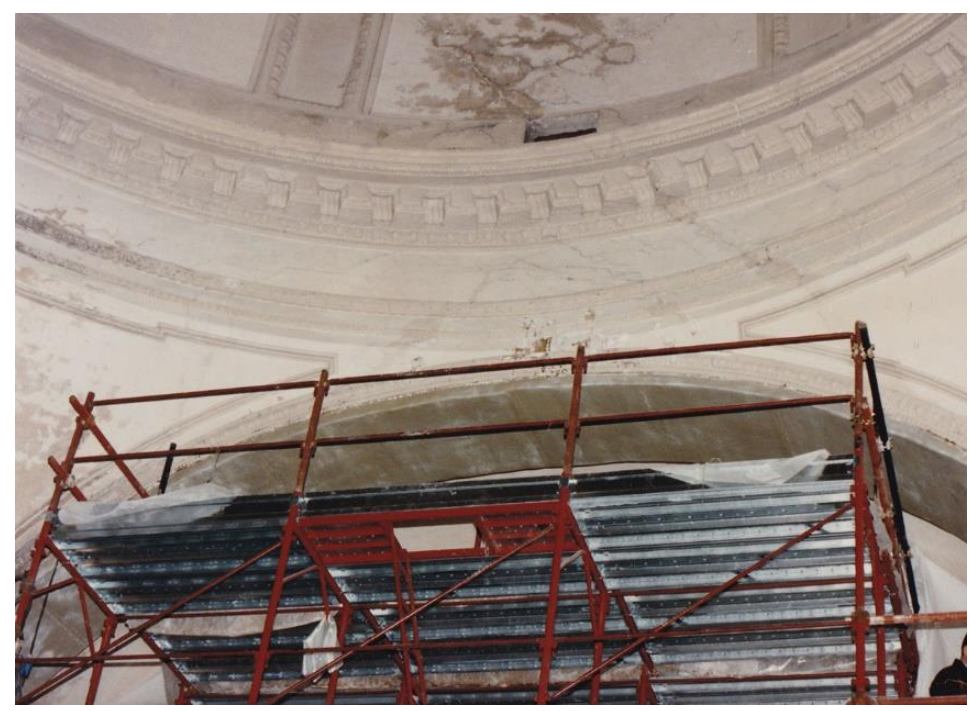

Figure 9. Application of GFRP intrados reinforcement bands on the triumphal arch.

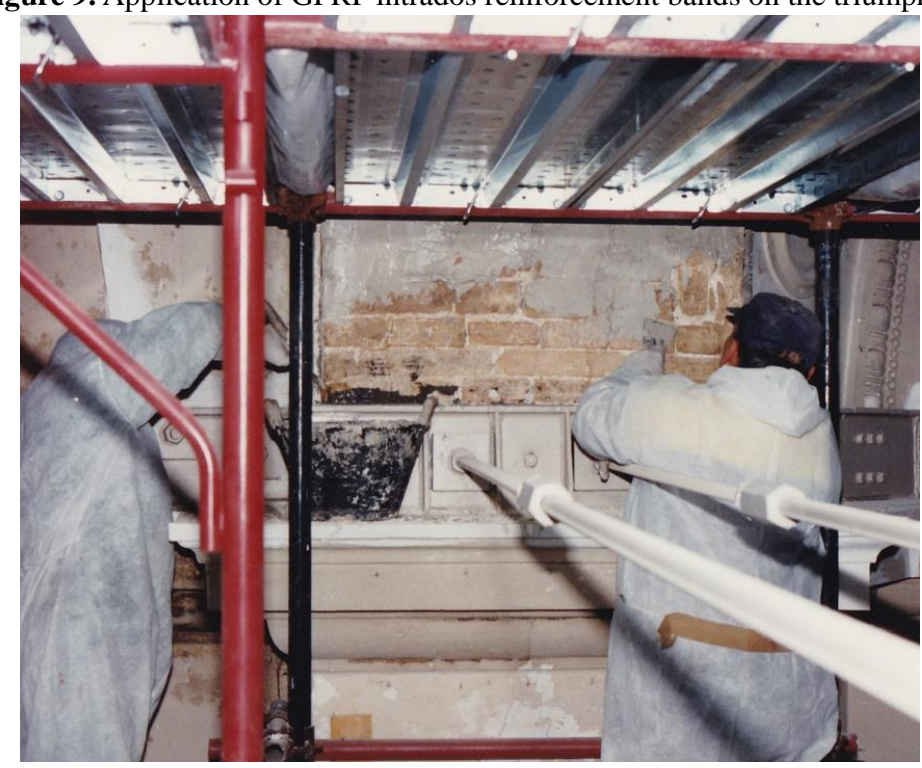

Figure 10. Strengthening work near the insertion of tie rods.

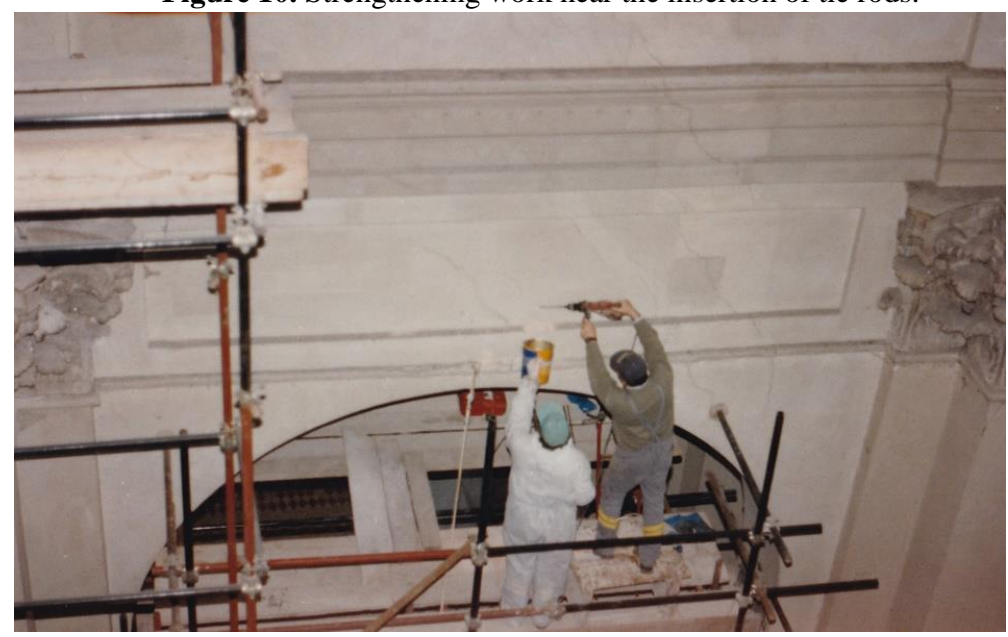

Figure 11. Injections technique for repair of existing cracks.

The reinforcement cycle with composite materials concerned the following processing steps. Removal of any plaster and all parts that were inconsistent or being detached, until a sound, compact and mechanically re- sistant support was obtained that does not lead to the separation of subsequent applications. Preparation of the substrate and the surface to be restored so as to eliminate any fragments present. Treatment of the surface by 
means of epoxy cortical consolidating fixative. If necessary, reconstruction of continuity material and regularization of the masonry surface by means of lime mortar. Wait for the drying of any regularization bands before proceeding with the subsequent application phase of the primer. First of all, application on the treated surface of two-component synthetic resin primer in aqueous dispersion (Figure 12). Subsequent application of solvent-free two-component thixotropic epoxy adhesive (Figure 13).

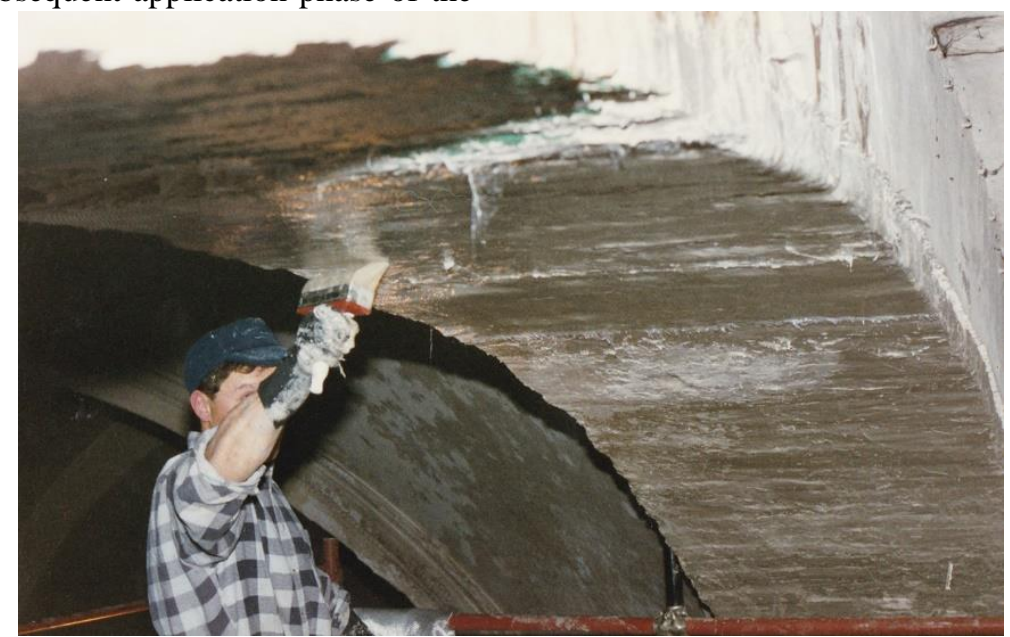

Figure 12. Application on the treated surface of two-component synthetic resin primer in aqueous dispersion.

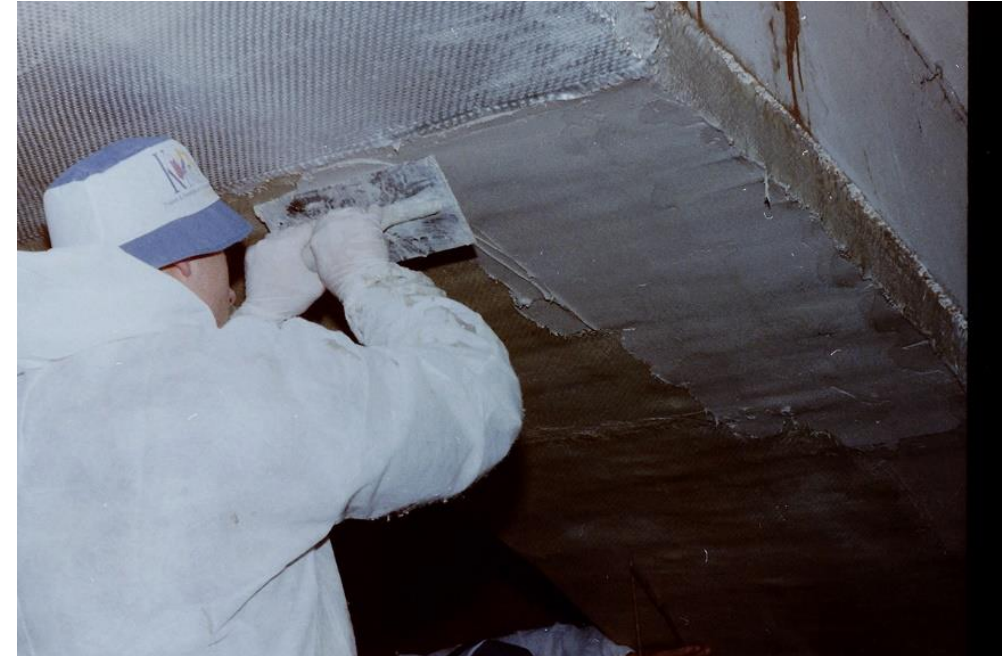

Figure 13. Application of solvent-free two-component thixotropic epoxy adhesive.

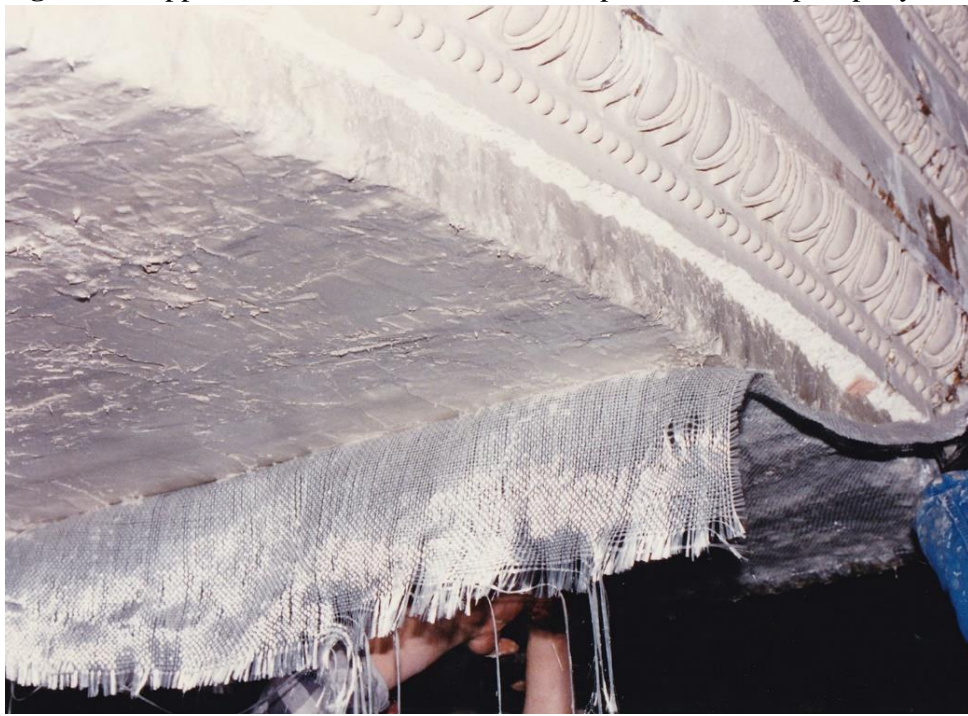

Figure 14. Intrados application of GFRP band for strengthening arch. 
The product had the function of levelling the surface to be reinforced and creating an adhesive layer for the subsequent application of the reinforcement. The application of the fabric occurred in the fresh air, applying fibre bands with an iron roller and exert a slight pressure, taking care not to create air bubbles (Figure 14). The fabric was pressed in the resin layer, using the roll for composites (always roll in the direction of the fibers, exerting slight pressure paying attention not to move the fabric during this phase). It was necessary to roll until the resin emerges between the fibers and impregnates them completely, forming a uniform layer on the fabric. It was very important to remove any air bubbles that may be trapped between the fabric and the substrate, continuing to roll in the direction of the fibers. Subsequent impregnation with solvent-free, two-component, fluid-containing epoxy resin applied by brush or roller in several coats and slowly so that the impregnation of the fabric was complete. Any further reinforcement layers should be applied fresh on fresh and immediately impregnated with resin.

Thanks to this series of structural reinforced work, during the 2016 Amatrice-Norcia earthquake the Spoleto Cathedral has not suffered any damage confirming the seismic improvement achieved (Figure 15).

\section{Discussion}

The primary objective of FRP strengthening technique is to increase the capacity of each structural member and the overall capacity of the masonry building. Strengthening methodologies consists of the application of FRP materials in the form of sheets installed on the members by adhesion and applied to the external surfaces of the masonry structure.

Design of FRP reinforcement shall ensure that the selected FRP system is always in tension. In fact, compression FRP is unable to increase the performance of the strengthened masonry member due to its small area compared to that of compressed masonry. FRP strengthening system shall be applied to structural members having suitable mechanical properties. If the masonry is damaged, not uniform, or cracked, it shall first be repaired with appropriate techniques to ensure a proper sharing of loads between support and FRP. Failure mode of FRP strengthened masonry structures usually involves a combination of the following mechanisms: excessive cracking due to tensile stresses in the masonry; crushing 8 | Alessandro Grazzini et al. of masonry; shear-slip of masonry; FRP rupture; FRP debonding.

Masonry can be considered an anisotropic material with a non-linear behavior. The stress-strain relationship may vary quite significantly depending on the blocks and on the type of mortar employed. Masonry exhibits a brittle behavior when subjected to tensile loading; the corresponding tensile strength is negligible compared to its compressive strength. It is assumed to neglect tensile strength of masonry ${ }^{[8]}$. FRP materials are characterized by an anisotropic behavior, when stressed in the fiber direction, FRP exhibits a linear elastic behavior up to failure. Bond between masonry and FRP is of great relevance because debonding yields to undesirable, brittle failure modes. FRP debonding shall always follow the post-elastic behavior of compressed masonry. If the tensile strength of the adhesive used to install FRP reinforcement is larger than that of the substrate, debonding between FRP and masonry takes place at the masonry face-level.

Structural members with single or double curvature generally lose their functionality due to the formation of hinges that promote the mechanisms of collapse. Hinges form in such masonry structures due to the negligible tensile strength of the masonry. Such hinges are located in regions of limited contact area, externally to the mid plane of the structure. As first approximation, they can be located either at the intrados or extrados of the masonry panel. A masonry hinge can carry axial and shear forces. As a result, the hinged section can only carry an axial force having an eccentricity equal to half of the structure thickness. FRP reinforcement delays both opening of cracks and formation of hinges within the masonry panel located on the opposite side with respect to the one where the FRP system is installed. Therefore, a properly anchored FRP reinforcement applied to the extrados (intrados) prevent the formation of hinges on the opposite side of the intrados (extrados). FRP reinforcement may be applied on the arch intrados to prevent the formation of hinges on the extrados.

The analysis of the progress of the compression pressures on the vault of the Spoleto Cathedral (Figure 16) have been studied by tracing the behavior of the vault to that of an arch with a thickness equal to $25 \mathrm{~cm}$ and unit width of 1 meter. The span of the vault was 11 meters and the arrow was 2,5 meters. The mechanical characteristics of the masonry were as follows from the 
Circolare 09/02/2009 ${ }^{[9]}$, divided by the confidence coefficient 1,35 relative to a limited level of knowledge of the structure, as suggest by the Italian Technical Codes:

$$
\begin{aligned}
& \mathrm{f}_{\mathrm{d}}=2,40 / 1,35=1,78 \mathrm{MPa} \\
& \tau_{0 \mathrm{~d}}=0,06 / 1,35=0,04 \mathrm{MPa} \\
& \mathrm{E}=1500 \mathrm{MPa} \\
& \mathrm{G}=500 \mathrm{Mpa}
\end{aligned}
$$

where $f_{d}$ was the design compressive strength, $\tau_{0 d}$

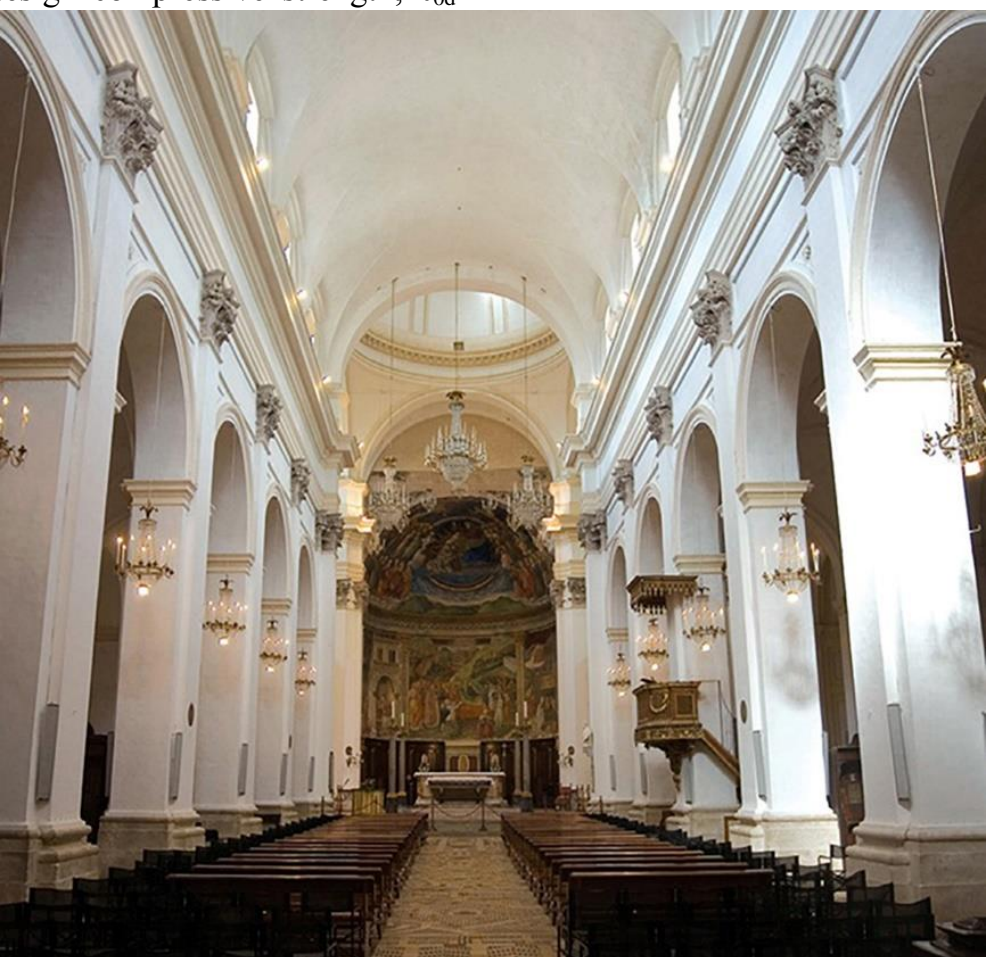

Figure 15. The interior of the Cathedral today after the safety work and after the 2016 Amatrice-Norcia earthquake.

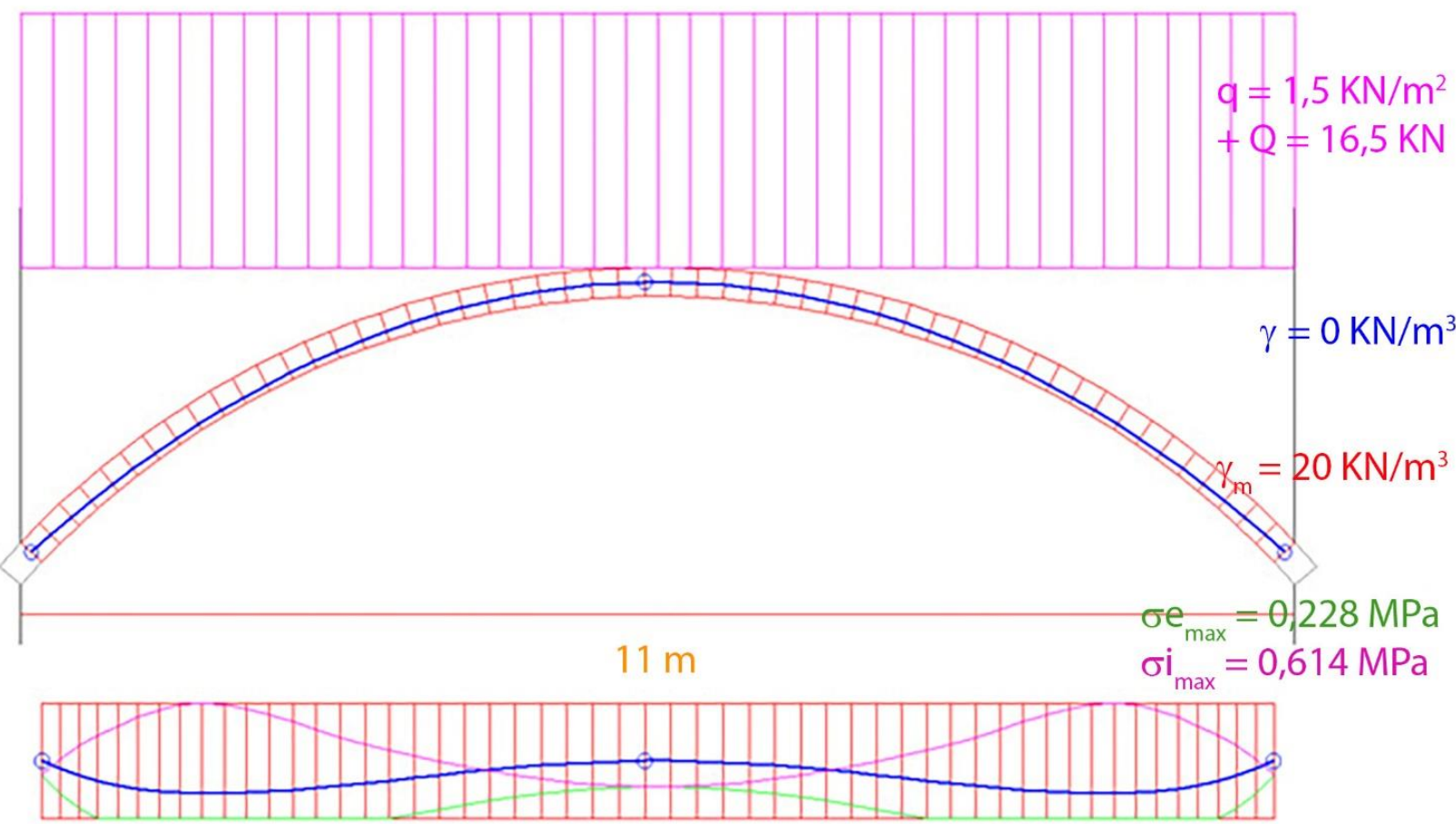

Figure 16. Pre-strengthening analysis of the masonry vault in Spoleto Cathedral. 


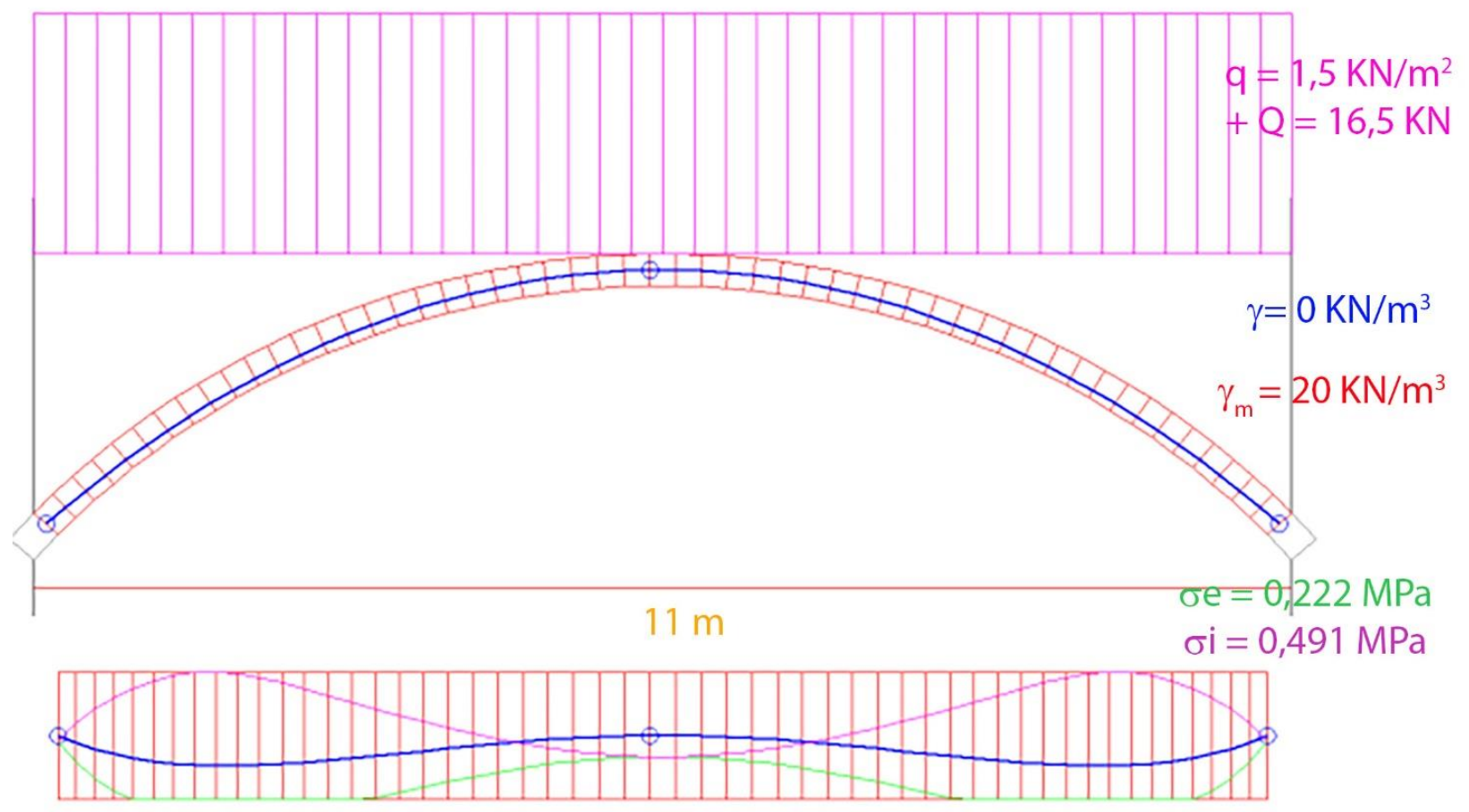

Figure 17. Strengthening analysis of the reinforced masonry vault in Spoleto Cathedral.

\section{Conclusions}

The bonding of the new composite materials represented an important novelty and alternative of strengthening interventions even within the structural restoration of monumental historical buildings. The FRP fabric compensates for the lack of tensile strength without increasing the seismic masses of the building. Therefore their use can be compatible also in monumental buildings, as an alternative to more invasive and heavy traditional strengthening work. The interesting case study of the Spoleto Cathedral has been analysed, demonstrating how strengthening techniques made by the gluing of glass fibre fabrics have guaranteed the preservation of the architectural heritage even after a subsequent major earthquake.

\section{Author contributions}

Alessandro Grazzini (A.G.) has followed the introductory part, the description of the materials and the strengthening techniques. Stefano Agnetti (S.A.) followed the description of the case study on the reinforcement works in the Spoleto cathedral.

\section{Acknowledgements}

The authors wish to thank Eng. Scatolini (works director) for technical information concerning the damage and strengthening techniques carried out, and the Arch- bishop of Norcia-Spoleto Monsignor Renato Boccardo for allowing and encouraging the scientific dissemination of the Spoleto cathedral.

Special thanks to Kimia's technical office for the precious research of the photographic and technical material of the restoration site.

\section{References}

1. Grazzini A, Chiabrando F, Foti S, Lingua A, Spanò A. Damage assessment and seismic vulnerability analysis of S. Agostino church in Amatrice. In Proceedings of the $16^{\text {th }}$ European Conference on Earthquake Engineering 2018, Thessaloniki, Greece, June 18-21.

2. Bocca P, Grazzini A, Masera D. Fatigue behaviour analysis for the durability prequalification of strengthening mortars. Journal of Physics: Conference $\quad$ Series 2011 ; 305. doi:10.1088/1742-6596/305/1/012041.

3. Marchetti L. La ricostruzione dei beni culturali in Umbria. Realizzazione e prospettive. Vol. 2 (in italian). Regione Umbria (Italy); 2007.

4. Corradi M, Borri A, Vignoli A. Strengthening techniques tested on masonry structures struck by the Umbria-Marche earthquake of 1997-1998. Constr. Build. Mater. 2002, 16(4): 229-239. https://doi.org/10.1016/S0950-0618(02)00014-4.

5. Benazzi G, Carbonara G. La cattedrale di Spoleto: storia arte conservazione (in italian). Federico Motta Editor. Milan (Italy); 2002.

6. www.kimia.it

7. Borri A, Castori G, Corradi M. Intrados strengthening of brick masonry arches with composite materials. Compos. B. Eng. 2011, 42(5): 1164-1172. doi: 
10.1016/j.compositesb.2011.03.005.

8. Luciano R, Sacco E. Homogenization technique and damage model for old masonry material. International Journal of Solids and Structures 1997; 34: 3191-3208.

9. Circolare 02/02/2009 n. 617: Istruzioni per l'applicazione delle «Nuove norme tecniche per le costruzioni» di cui al decreto ministeriale 14 gennaio 2008. Gazzetta ufficiale 26/02/2009 n. 47. Ministero delle Infrastrutture, Roma, Italy. 